\title{
Depression among Chronic Kidney Diseases Patients Receiving Hemodialysis
}

\author{
Shanti Khadka, ${ }^{1}$ Rita Adhikari, ${ }^{2}$ Tarun Paudel $^{3}$ \\ ${ }^{1}$ Act. Matron, Department of Nursing; ${ }^{2}$ Senior Staff Nurse, Neonatal Care Unit, Western Regional Hospital, \\ Pokhara Academy of Health Sciences; ${ }^{3}$ Professor, Karnali Academy of Health Sciences, Jumla, Nepal \\ *Corresponding Author: Shanti Khadka, Email: khadka2shanti@gmail.com
}

\begin{abstract}
Background: Chronic Kidney Disease (CKD) is a progressive irreversible loss of renal function over a period of months or years. When kidney disease progresses, it may eventually lead to kidney failure, which requires dialysis or a kidney transplant to maintains life. Hemodialysis is used for patients who require short term dialysis (days to weeks) and for patients with advanced CKD and End Stage renal Disease (ESRD) who require long term or permanent renal replacement therapy. Hemodialysis significantly and adversely affects the lives of patients, both physically and psychologically. Depression is the most common psychological condition among patients with ESRD. Depression in dialysis patients not only effect mortality, but increased rate of hospitalizations and dialysis withdrawal is also very common.
\end{abstract}

Methods: A descriptive cross sectional research design was carried out to identify the depression level of chronic kidney disease patients receiving Hemodialysis in Western Regional Hospital, Pokhara using Beck Depression Inventory among forty six patients.

Results: The study findings revealed that majority of the patients $(84.8 \%)$ has various degree of depression i.e. mild $(21.7 \%)$, moderate $(30.8 \%)$ and severe $(32.6 \%)$. Only fifteen percent of patient has no depression. There was no statistical association between the level of depression and socio-demographic variables. It can be concluded that the prevalence of depression is high among patients receiving Hemodialysis.

Conclusion: The prevalence of depression is high among patients receiving Hemodialysis. It is effective to provide mental health services to the CKD patients receiving Hemodialysis which help them better psychologically adaptation to their disease and improve their quality of life.

Keywords: Chronic kidney disease; Depression; Hemodialysis

\begin{tabular}{|c|c|c|}
\hline \multicolumn{2}{|c|}{ Access this article Online } & Article Info. \\
\hline Quick Response Code & Website: & How to cite this article in Vancouver Style? \\
\hline & www.jkahs.org.np & $\begin{array}{l}\text { Khadka S, Adhikari R, Paudel T. Depression Among } \\
\text { Chronic Kidney Diseases Patients Receiving Hemodialysis. } \\
\text { Journal of Karnali Academy of Health Sciences 2020;3(2): } \\
73-79\end{array}$ \\
\hline \& $\mathrm{V}$ & $\begin{array}{l}\text { DOI: } \\
\text { https://doi.org/10.3126/ } \\
\text { jkahs.v3i2.31326 }\end{array}$ & $\begin{array}{ll}\text { Received } & : 2 \text { April } 2020 \\
\text { Accepted } & : \text { 25 June } 2020 \\
\text { Published Online } & : 26 \text { June } 2020 \\
& \\
\text { Conflict of Interest } & : \text { None } \\
\text { Source of Support } & : \text { None }\end{array}$ \\
\hline
\end{tabular}




\section{INTRODUCTION}

Chronic Kidney Disease (CKD) is a slow and progressive irreversible deterioration in renal function in which the body's ability to maintain metabolic and fluid and electrolyte balance fails, resulting in uremia or azotemia. ${ }^{1}$ Chronic Kidney Disease (CKD) is a common and rapidly increasing public health problem all over the world, both in developed and developing countries. The incidence of End Stage Renal Disease (ESRD) is estimated to be 100 per million populations in South Asian countries Pakistan, India and Banglades. ${ }^{2}$

The most common causes of CKD are diabetic nephropathy, hypertension and glomerulonephritis. Dialysis is the process of removing nitrogenous waste products and excess water from the body. ${ }^{3}$

CKD has affected about $10 \%$ of population worldwide and millions die each year. The prevalence is higher among elder people (aged 65 through 74 ) one in five men and one in four women has CKD. ${ }^{4}$

Hemodialysis is used for patients requiring temporary and permanent renal replacement therapy to prevent from death. Hemodialysis does not replace the lost renal endocrine and metabolic function. About nine in ten patients who require long term renal replacement therapy are on chronic dialysis. ${ }^{1}$

In Nepal, renal disease ranks as sixth among the non communicable disease. It was estimated that approximately 2.6 million populations could be suffering from some degree of kidney illness and approximately 2,600 people might have suffered from chronic renal failure. Approximately 600 to 1,000 patients with chronic kidney failure attend the hospitals every year for Hemodialysis. ${ }^{5}$

Depression has been identified as the primary mental health problem among dialysis patients, with a $2-$ 10 times higher prevalence, compared to the general population. ${ }^{6}$

A cross-sectional study conducted in a tertiary care private hospital in Kollam district, Kerala. One hundred and twenty-one people undergoing hemodialysis were included in this study to assess depression in this population. Depression was evaluated using the Beck Depression Inventory
(BDI). Among the patients, 33 (27.3\%) were suffering from mild depression, 49 (40.5\%) were suffering from moderate depression, and 19 (15.7\%) had severe depression. ${ }^{7}$

A cross-sectional prospective study conducted at Hemodialysis unit of Shalamar Hospital and Shaikh Zayed Hospital, Lahore from 1st January 2006 to 30th April 2006. All patients getting regular hemodialysis for more than three months were included. Eighty nine patients were enrolled which included fifty two (58.4\%) were male and seventy seven $(86.5 \%)$ were married. Severity of depression was categorized in to mild, moderate and severe on the basis of BDI score. Mean depression scale was 19.64. Fifteen (27\%) were mild, twenty three $(25.8 \%)$ moderately and twenty seven $(30.3 \%)$ were severely depressed. It was observed that the risk factors; marital status, education, number of children, financial support have significant association with depression. ${ }^{8}$

\section{MATERIALS AND METHODS}

A descriptive cross sectional research design was carried out to identify the depression level of chronic kidney disease patients receiving Hemodialysis in Western Regional Hospital, Pokhara. At the time of data collection there were 48 patients receiving hemodialysis altogether. Two patients were excluded from the study as they were unable to give informed consent because of mental problem. A total number of 46 patients receiving hemodialysis were selected by using consecutive sampling technique. Beck Depression Inventory was used to find out depression level.

Grading of depression was done according to severity levels: Nil (less than 9 depression scale), mild (depression scale 10-15), moderate (16 24 depression scale) and severe (25 and above). ${ }^{8}$ Permission to conduct study was obtained from the authority of WRH through a written request letter. Verbal informed consent was obtained from the subjects prior to data collection. Data were collected by the researchers from $11^{\text {th }}$ February to $17^{\text {th }}$ February 2018.The collected data were organized, coded and entered in SPSS 16 version and analyzed by using descriptive statistics like frequency, percentage, 
mean and standard deviation. The inferential statistics like chi square test was used to find the associations between related variables and level of depression.

\section{RESULTS}

The socio-demographic characteristics of the respondents reveal that seven out of ten were male $(69.6 \%)$, and literate $(71.7 \%)$. The highest proportions $(38.5 \%)$ of the respondents were below 40 years $(38.5 \%)$ and from rural areas $(56.5 \%)$. The percentage of married respondents was about eighty five. Three out of four patients have the duration of dialysis 1 to 2 years. All the patients were unemployed and cared by family members i.e. husband, wife, son, daughter in laws, and parents. (Table 1)

\section{Table 1: Socio-demographic Characteristics of the Respondents}

\begin{tabular}{|c|c|c|}
\hline Variables & Frequency & Percentage \\
\hline \multicolumn{3}{|l|}{ Age: } \\
\hline 19-39 Years & 18 & 39.10 \\
\hline 40-59 Years & 21 & 45.70 \\
\hline 60 Years and above & 07 & 15.20 \\
\hline \multicolumn{3}{|l|}{ (Mean \pm SD: $45.41 \pm 14.27$} \\
\hline \multicolumn{3}{|l|}{ Mini:19, Max: 81) } \\
\hline \multicolumn{3}{|l|}{ Sex: } \\
\hline Male & 32 & 69.60 \\
\hline Female & 14 & 13.40 \\
\hline \multicolumn{3}{|l|}{ Residence: } \\
\hline Rural & 26 & 56.50 \\
\hline Urban & 20 & 43.50 \\
\hline \multicolumn{3}{|l|}{ Marital status } \\
\hline Married & 39 & 84.80 \\
\hline Unmarried & 07 & 15.20 \\
\hline \multicolumn{3}{|l|}{ Educational status: } \\
\hline Illiterate & 13 & 28.30 \\
\hline Literate & 33 & 071.7 \\
\hline \multicolumn{3}{|l|}{ Duration of dialysis (in years): } \\
\hline 1 to 2 Years & 35 & 76.10 \\
\hline 2 years and more & 11 & 23.90 \\
\hline \multicolumn{3}{|l|}{ (Mean \pm SD: $02.43 \pm 01.64$} \\
\hline Mini:1, Max 9) & & \\
\hline
\end{tabular}

According to the responses of the respondents to Beck Depression Inventory, majority (54.30\%) feel sad much of the time, don't criticize or blame themselves more than usual and doesn't have thought of killing themselves. Three out of five $(61.50 \%)$ of them feel discouraged about their future. About one third (34.80\%) of respondents felt failed more than they should have $(34.8 \%)$ and reported that they were agitated (32.6\%). Fifty two percent of respondents don't enjoy things as much as they used to. Likewise, 45.7 percent of them don't feel they are particularly guilty for being ill, not lost interest in other people and sleep as usual but feel that they are being punished. Four out of ten (39\%) respondents lost confidence by themselves. Similarly, Only 43.50 percent of the respondents do not cry anymore than usual, make decision about as well as they ever could, have less energy than they used to have 
and can't concentrate as well as usual but get tired more easily than they used to. Thirty nine percent don't consider themselves as worthwhile. Two third $(65.20 \%)$ respondents are slightly more irritated now than usual. Fifty percent of respondents have their appetite much less than before. Only 30.40 percent have noticed less interested in sex than they used to be. (Table 2)

Table 2: Response of respondents to Beck Depression Inventory Frequency (\%) n= 46

\begin{tabular}{|l|c|c|c|c|}
\multicolumn{1}{|c}{ Response } & 0 & 1 & 2 & 3 \\
\hline Sadness & $15(32.60)$ & $25(54.30)$ & $5(10.90)$ & $01(2.20)$ \\
\hline Pessimism & $11(23.90)$ & $25(54.30)$ & $04(8.70)$ & $06(13.00)$ \\
\hline Past failure & $22(47.80)$ & $16(34.80)$ & $04(8.70)$ & $04(8.70)$ \\
\hline Loss of pleasure & $11(23.90)$ & $24(52.20)$ & $04(8.70)$ & $07(15.20)$ \\
\hline Guilty feelings & $21(45.70)$ & $19(41.30)$ & $03(6.50)$ & $03(6.50)$ \\
\hline Punishment feelings & $21(45.70)$ & $19(41.30)$ & $04(8.7)$ & $02(4.30)$ \\
\hline Self dislike & $14(30.40)$ & $18(39.10)$ & $13(28.30)$ & $01(2.20)$ \\
\hline Self criticalness & $25(54.30)$ & $11(23.90)$ & $13(28.30)$ & $01(2.20)$ \\
\hline Suicidal thoughts & $25(54.30)$ & $17(37.00)$ & $03(6.50)$ & $01(2.20)$ \\
\hline Crying & $20(43.50)$ & $11(23.9)$ & $03(6.50)$ & $12(26.10)$ \\
\hline Agitation & $10(21.70)$ & $6(13.00)$ & $15(32.60)$ & $15(32.60)$ \\
\hline Loss of interest & $21(45.70)$ & $15(32.60)$ & $04(8.70)$ & $06(13.00)$ \\
\hline Indecisiveness & $20(43.50)$ & $6(13.00)$ & $12(26.10)$ & $08(17.40)$ \\
\hline Worthlessness & $17(37.00)$ & $18(39.10)$ & $95(10.90)$ & $06(13.00)$ \\
\hline Loss of energy & $04(8.70)$ & $20(43.50)$ & $10(21.7)$ & $12(26.10)$ \\
\hline Changes in sleeping pattern & $09(19.60)$ & $21(45.70)$ & $09(19.6)$ & $07(15.20)$ \\
\hline Irritability & $12(26.10)$ & $30(65.20)$ & $03(6.50)$ & $01(2.20)$ \\
\hline Change in appetite & $12(26.10)$ & $23(50.00)$ & $09(19.60)$ & $02(4.30)$ \\
\hline Concentration difficulty & $18(39.10)$ & $20(43.50)$ & $06(13.00)$ & $02(4.3)$ \\
\hline Tiredness or fatigue & $04(8.70)$ & $20(43.50)$ & $13(28.30)$ & $09(19.60)$ \\
\hline Loss of interest in sex & $04(8.70)$ & $14(30.40)$ & $18(39.10)$ & $10(21.70)$ \\
\hline
\end{tabular}

This study reveals that majority of the patients (84.8\%) has various degree of depression i.e. mild (21.7\%), moderate (30.8\%) and severe (32.6\%). Only 15 percent of patient has no depression. (Table 3)

Table 3: Depression Level of the Respondents:

\begin{tabular}{|c|c|c|}
\hline Depression Level & Frequency & Percent \\
\hline Normal & 07 & 15.2 \\
\hline Mild & 10 & 21.7 \\
\hline Moderate & 14 & 30.8 \\
\hline Severe & 15 & 32.6 \\
\hline
\end{tabular}

The residence, marital status, educational status and duration of dialysis are statistically not significant to depression $(P=0.000)$. (Table 4$)$ 
Table 4: Associations between Socio-demographic characteristics and depression among Hemodialysis patients

\begin{tabular}{|c|c|c|c|c|}
\hline \multirow{2}{*}{$\begin{array}{c}\text { Socio-demographic } \\
\text { variables }\end{array}$} & \multicolumn{2}{|c|}{ Depression } & \multirow{2}{*}{$\chi^{2}$ value } & \multirow{2}{*}{ p value } \\
\hline & Normal & Depression & & \\
\hline \multicolumn{5}{|l|}{ Residence } \\
\hline Rural & 04 & 22 & 0.001 & .971 \\
\hline Urban & 03 & 17 & & \\
\hline \multicolumn{5}{|l|}{ Marital status } \\
\hline Married & 06 & 33 & 0.006 & 0.941 \\
\hline Unmarried & 01 & 06 & & \\
\hline \multicolumn{5}{|l|}{ Educational status } \\
\hline Illiterate & & 13 & 3.253 & .071 \\
\hline Literate & 7 & 26 & & \\
\hline \multicolumn{5}{|l|}{ Duration } \\
\hline$<2$ years & 05 & 30 & & \\
\hline$>2$ years & 02 & 09 & .98 & .754 \\
\hline
\end{tabular}

$* P<0.05$ statistically significant values

\section{DISCUSSION}

This study revealed that mean depression scale was 23.39 and prevalence of depression was high (85\%).The findings of the study is consistent with the finding revealed by Pramiladevi (72.7\%). ${ }^{11}$ and Hamody et al. $(80 \%)^{15}$ but inconsistent with the findings of Rana et al. (40\%) ${ }^{12}$ and Armaly $(43.7 \%) .^{9}$ This study revealed that the degree of depression is mild (21.7\%), moderate (30.8\%) and severe (32.6\%). Only 15 percent of patient has no depression which was consistent with the study of Abdul Rhman, where prevalence of depression among hemodialysis patients showed $16.5 \%$ had no depression, $25.6 \%$ had mild, $45.9 \%$ had moderate and $12 \%$ had severe depression..$^{13}$ This finding was also similar with the findings of Anjomshoa et al. which showed that $29 \%, 30 \%$ and $27.4 \%$ of the total participants were suffering from mild, moderate and severe levels of depression ${ }^{14}$ and the findings of Hamody et al., which showed that the participants had $25 \%, 50 \%$ and $25 \%$ mild, moderate and severe levels of depression respectively. ${ }^{15}$

The finding was also consistent with the finding of Nelson V, Gopalakrishnan s, Simon S, et.al. ${ }^{7}$ which showed that $33(27.3 \%)$ were suffering from mild depression, 49 (40.5\%) were suffering from moderate depression, and 19 (15.7\%) had severe depression and Anees M, Barki H, Masood M, et.al. revealed that Mean depression scale was 19.64. Fifteen (27\%) were mild, twenty three $(25.8 \%)$ moderately and twenty seven (30.3\%) were severely depressed. ${ }^{8}$ The finding of the study also consistent with the study of Cengic \& Resic, which showed $51 \%$ of the HD patients had depression in various degrees i.e. $30 \%$ had mild depression, $8.5 \%$ had moderate depression and $12.5 \%$ had severe depression. ${ }^{10}$

This study findings was inconsistent with the findings of Rana et al. which revealed that (mild $=35 \%$, moderate $=40 \%$ and severe $=25 \%$ ). ${ }^{12}$ The findings was also inconsistent in the study done by Salehi $\mathrm{M}$, which revealed that $50 \%$ of the patients had depression of which, $33.3 \%$ suffered from mild depression, $15 \%$ from moderate and $1.7 \%$ suffered from severe depression. ${ }^{16}$

The present study revealed that age, sex, residence, marital status, educational status and duration of dialysis were not statistically significant to level of depression which was supported by the findings of Salehi M, which reported that there was no significant difference between the two groups of depressed and non-depressed patients across gender, age, marital status and duration of dialysis. ${ }^{16}$ The findings was also 
consistent with the study of Cengic \& Resic (2010) where the gender, marital status and hemodialysis duration did not influence significantly in occurrence of depression ( $\mathrm{p}>0.05) .{ }^{10}$

This findings was inconsistent with the findings of Pramiladevi where depression found to be highly significant in patients who were educated and who were on dialysis for less than 1 year. ${ }^{11}$ This finding was also inconsistent with a study of Rai, which revealed that depression was significantly more in patients with those on dialysis for more than 1 year $(P=0.001)$ and the unemployed $(P=0.009) .{ }^{17}$ Similarly, the finding of this study was contradict to the study of Armaly, which shows that the frequency of depression was two-fold higher among young female patients ( $\mathrm{n}=8$, age $=27$ years) undergoing hemodialysis for at least 12 months compared to adulthood female hemodialysis patients $(\mathrm{n}=29$, age. 27 years, $P<0.01)$. Depression was twofold higher among unmarried patients $(\mathrm{n}=43)$ versus married patients $(\mathrm{n}=28, P=0.003)$, and threefold higher among illiterate patients $(\mathrm{n}=33)$ versus literate patients $(\mathrm{n}=38, P=0.001){ }^{9}$

\section{CONCLUSION}

The prevalence of depression is high among patients receiving Hemodialysis. It is therefore need to develop systematic approaches to psychiatric screening of patients for mental illness, and then planning treatment strategies. It is effective to provide mental health services to the CKD patients receiving Hemodialysis which help them better psychologically adaptation to their disease. Findings have implications in improving the quality of dialysis patients with depression.

Acknowledgement : We would like to acknowledge patients of Hemodialysis departments in Pokhara Academy of Health Science, Western Regional Hospital for their important contribution to the study.

\section{REFERENCES}

1. Smeltzer SC, Bare BG, Hinkle JL, Cheever KH. Brunner and Suddarth's textbook of medicalsurgical nursing. 12th ed. Philadelphia: Lippincott Williams \& Wilkins; 2010.p. 1282- 1337.
2. Hada RK, Khakurel S, Agrawal RK, Kafle RK, Bajracharya SB, Raut KB. Incidence of end stage renal replacement therapy in Nepal. Kathmandu Univ Med J. 2009; 7: 301-305.

3. Webmed. Chronic Kidney Disease - Cause https://www.webmd.com/a-to-z-guides/tc/ chronic-kid

4. National Kidney foundation; Global Facts: About Kidney Disease 2015 Available from: https://www.kidney.org/kidneydisease/globalfacts-about-kidney-disease

5. Hirachan P, Kherel T, Sha DS, Ball J.Renal transplant therapy in Nepal. The official journal of international society for Hemodialysis. 2010; 14: 383-386.

6. Watnick, S., Kirwin, P., \& Mahnensmith, R. The Prevalence and Treatment Of Depression Among Patients Starting Dialysis.2003. American Journal of Kidney Diseases,41, 105110.

7. Nelson V, Gopalakrishnan s,Rakesh PS,Vikram V, Simon S, Abhram S et.al. Depression Among Dialysis Patients. National Kidney Foundation Journal of Nephrology Social Work; 40(2)

8. Anees M, Barki H, Masood M, Mumtaz A, Kausar T. Depression in hemodialysis patients. Pak J Med Sci 2008;24(4):560-5

9. Armaly Z, Farah J, Jabbour A, Bisharat B, Qader AA, Saba S, et al. Major depressive disorders in chronic hemodialysis patients in Nazareth: identification and assessment. Neuropsychiatric disease and Treatment. 2012

10. Cengic B, Resic H. Depression in hemodialysis patients. Sarajevo Bosnia;2010.p.73-78

11. Pramiladevi R, Goornave SM, Shreeram K. Depression in patients in hemodialysis in Bagalcot. Medica Innovatica. 2012; 1(2): 5-11.

12. Rana R, Sharma D, Sushil C, Vijayvergia D, Lamba R. Depression in Dialysis2010. 
13. AlDukhayel. Prevalence of depressive symptoms among hemodialysis and peritoneal dialysis patients. International Journal of Health Sciences, QassimUniversity.2015 9(1):10-16

14. Depression among hemodialysis patients.Iran. 2014 (1):24-28

15. Hamody AR, Kareem AK, Al-Yasri AR, Sh. Ali AA. Depression in Iraqi hemodialysis patients. Arab Journal of Nephrology and Transplantation. 2013 6(3):169-72.
16. Salemi M, Noormohammadi-Sarabi A. Prevalence of depression in hemodialysis patients of ShahidHashemiNejadHospital. Iranian Journal of Psychiatry and Clinical Psychology. 2003[cited 21 January]; 8(3):2025.

17. Rai M, Rustagi T, Rustagi S, Kohil R. Depression, insomnia and sleep apnea in patients on maintenance hemodialysis. 2011[cited $21^{\text {st }}$ January]; 21(4):223-229. 